UCRL-ID-121253

\title{
Status Report on Method and Results for New Discriminants and Combinations of Discriminants for Different Ranges
}

Peter Goldstein

April 7, 1995

Work performed under the auspices of the U.S. Department of Energy by the Lawrence Livermore National Laboratory under Contract W-7405-Eng-48. 


\section{DISCLAIMER}

Portions of this document may be illegible in electronic image products. Images are produced from the best available original document. 


\title{
Status Report on Method and Results for New Discriminants and Combinations of Discriminants for Different Ranges
}

\author{
Peter Goldstein \\ Lawrence Livermore National Laboratory
}

Introduction

As part of our effort to improve seismic monitoring capabilities, the Lawrence Livermore National Laboratory (LLNL) CTBT R\&D program has been developing a number of new seismic discriminants. We are also investigating their sensitivity to distance and developing models to describe their physical basis.

Conventional Discriminants and the need for new discriminants:

A number of discriminants have been developed for seismic monitoring. These include the Ms-mb discriminant which measures differences in surface and body wave magnitudes (e.g., Marshall and Basham, 1972), short period $P$ to $S$ wave amplitude ratio discriminants (e.g., Blandford, 1981) and spectral ratios discriminants (e.g., Murphy and Bennett, 1982). Unfortunately, existing discrimination capabilities are insufficient to meet the needs that will be required by a comprehensive test ban treaty (CTBT). Of particular concern are limitations of current capabilities for discriminating small magnitude $(\mathrm{mb}<4)$ seismic events such as earthquakes, mining explosions, and mining related seismicity (rockbursts and collapse events) from small magnitude nuclear explosions (both coupled and decoupled). In this report, we summarize our work on the development of new methods for discriminating such small magnitude events.

New Discriminants

The new discriminants we are developing at LLNL include empirical methods and model based techniques. Among the more 
promising empirical methods is one that looks for differences in the slope of $P$ to $S$-wave spectral ratios (Goldstein et al., 1994). We have found that this method discriminates NTS earthquakes and explosions very well and may also distinguish explosions and rockbursts (Figure 1). Of particular importance, this method can discriminate shallow small magnitude earthquakes. Such events have been found to be problematic for most conventional discriminants. We have also been investigating a discriminant which combines $P$ to $S$-wave spectral slopes and more conventional $P$ to $S$-wave spectral ratios. These discriminants work better in combination, than separately, because they are partially uncorrelated with each other. The above techniques are described in detail in the attached report.

Another empirical method, being developed at LLNL, looks for low frequency peaks in the spectra of an events coda. Based on NTS data, this method appears to work very well, especially above magnitudes of approximately 3.5 (Mayeda et al., 1994). Dowla (1994) describes some of the work we are doing at LLNL developing a variety of pattern recognition techniques using neural networks. These techniques use whole waveforms from existing data to define patterns for different categories of events.

Promising model-based methods include the moment-magnitude discriminant (e.g., Patton and Walter, 1993) and waveform modeling. These discriminants are particularly important because they are based on a physical model. In principal, knowledge of the physics underlying a particular discriminant will allow us to asses its applicability and probable success in new regions or in regions where limited ground truth data exists. In closely related work, we are developing a physical basis for these and other more conventional discriminants (Walter et al., 1994).

In addition to the aforementioned work, a number of contractors and other organizations are pursuing improvements to conventional discriminants and developing new discriminants. For example, Blandford (1993) has developed an earthquakeexplosion discriminant based on differences in the shape of regional P waveforms. Woods and Helmberger (1994) propose a discriminant based on the ratio of short-period to long-period 
seismic energy. Herrin (1994) has proposed an improvement to the Ms-mb discriminant which uses autoregressive methods to estimate the surface wave magnitude from low signal to noise ratio data.

\section{Su m mar y :}

We are in the process of developing a number regional discriminants which have the potential to significantly improve the global CTBT monitoring capability and our ability to identify events of special interest. Future work will include further testing of these discriminants, investigation of a variety of proposed discriminants and development of models describing the physical basis for new and existing discriminants.

\section{Figure Caption:}

Figure 1. Slopes of $\mathrm{Pn} / \mathrm{Lg}$ spectral ratios for NTS explosions and earthquakes, and a few western US rockbursts. Explosions in low, and high gas-filled porosity are indicated by the black plusses and red crosses, respectively. Shallow and Normal depth earthquakes are indicated by green, open squares and blue, open circles, respectively. Rockbursts are indicated by pink, open triangles.

\section{References:}

Blandford, R. R., Seismic Discrimination Problems at Regional Distances, NATO, Advanced Study Institutes, Series C, 74, D. Reidel Publishing Company, Dordrecht, Holland, 1981.

Blandford, R. R., Discrimination of Earthquakes and explosions at regional distances using complexity, AFTAC-TR-93-044, HQ AFTAC, Patrick AFB FL, (1993)

Dowla, F. U., Neural Networks in Seismic Discrimination, Lawrence Livermore National Laboratory, Livermore, CA, UCRL-JC-119218.

Herrin, E., V. Burlacu, H. Gray, J. Swanson, P. Golden, B. Myers, Research in regional event discrimination using Ms:mb and 
autoregressive modeling of $\mathrm{Lg}$ waves, in Proceeding of the 16th Annual Seismic Research Symposium, PL-TR-94-2217, 1994.

Marshall, P.E. and P.W. Basham, Discrimination between earthquakes and underground explosions employing an improved Ms scale, Geophys. J. R. Astron. Soc., 28, 431-458, 1972.

Mayeda, K. M., W. R. Walter, P. Goldstein, Depth dependent spectral peaking for NTS explosions from broadband $\mathrm{Lg}$ coda, EOS Supplement, 75, 432, 1994.

Murphy, J. R., and J. J. Bennett, A discrimination analysis of shortperiod regional seismic data recorded at Tonto Forest Observatory, Bull. Seis. Soc. Am., 72, 1351-1366, 1982.

Patton, H. J., and W. R. Walter, Regional moment:magnitude relations for earthquakes and explosions, Geophys. Res. Lett., 20, $277-280,1993$

Walter, W. R., P. Goldstein, K. M. Mayeda, H. J. Patton, The basis of earthquake and explosion discrimination at the Nevada Test Site using phase and spectral ratios, EOS Supplement, 75, 432, 1994.

Woods, B. W., and D. V. Helmberger, Regional seismic discriminants using wavetrain energy ratios, in Proceeding of the 16th Annual Seismic Research Symposium, PL-TR-94-2217, 1994. 


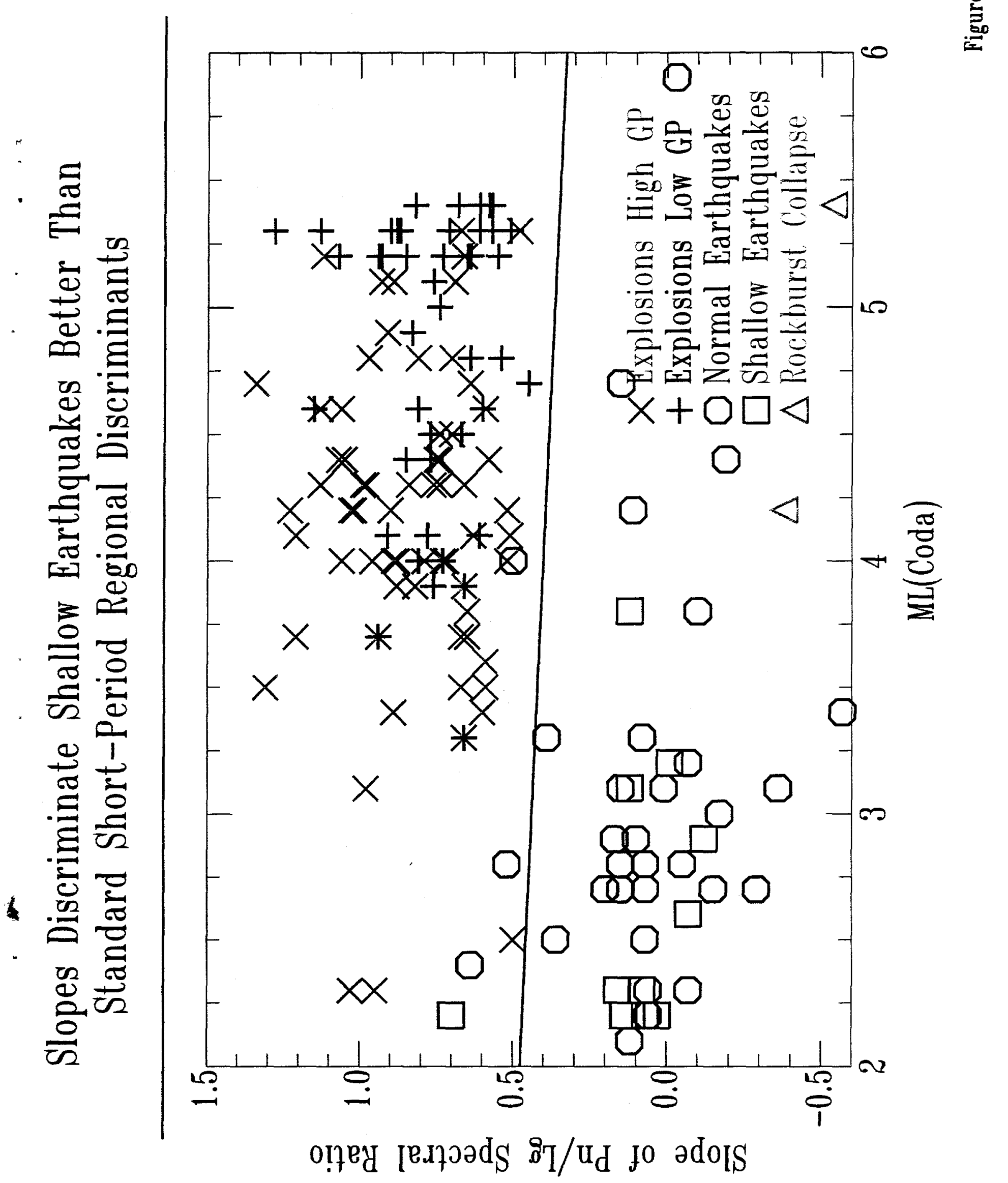

